Check for updates

Cite this: RSC Adv., 2018, 8, 30171

Received 4th July 2018

Accepted 19th August 2018

DOI: $10.1039 / c 8 r a 05714 a$

rsc.li/rsc-advances

\title{
Preparation of high-yield N-doped biochar from nitrogen-containing phosphate and its effective adsorption for toluene $\uparrow$
}

\author{
Qiying Zhou, ${ }^{a}$ Xia Jiang, (D) *ab $\mathrm{Xi} \mathrm{Li}^{\text {a }}$ Charles Qiang Jia ${ }^{\mathrm{c}}$ and Wenju Jiang ${ }^{\mathrm{ab}}$
}

Novel biochar was prepared from plant-based biomass by the addition of nitrogen-containing phosphates (NCPs), including ammonia phosphate (AP), ammonia polyphosphate (APP) and urea phosphate (UP). The results demonstrated that with the addition of NCPs, the yield of biochar could be significantly increased from about $30 \%$ to up to about $60 \%$. The pore structure of the biochar was significantly improved, and the AP-prepared biochar obtained a higher $S_{\mathrm{BET}}$ and $V_{\text {tot }}$ of $798 \mathrm{~m}^{2} \mathrm{~g}^{-1}$ and $0.464 \mathrm{~cm}^{3} \mathrm{~g}^{-1}$, respectively. Moreover, the surface chemistry of the NCP-prepared biochar was affected, and N heteroatoms could be successfully doped on the surface of biochar, up to $4.16 \%$. Furthermore, through TG-FTIR and XPS analysis, some possible interactions between plant-based biomass and NCPs during the pyrolysis process were proposed to explore the mechanisms of the preparation process, including the $\mathrm{P}$ route and $\mathrm{N}$ route, in which the $\mathrm{H}_{3} \mathrm{PO}_{4}$ and $\mathrm{NH}_{3}$ gradually generated during the heating process played the dominant roles for the high yield N-doped biochar. All the NCP-prepared biochar presented good toluene adsorption capacities from 175.9 to $496.2 \mathrm{mg} \mathrm{g}^{-1}$, which were significantly higher than that of blank char $\left(6.5 \mathrm{mg} \mathrm{g}^{-1}\right)$.

\section{Introduction}

The emission control of volatile organic compounds (VOCs) has aroused great attention, due to their toxicity, carcinogenesis, and/or mutagenicity. Many techniques, such as catalytic oxidation, $^{\mathbf{1 , 2}}$ adsorption ${ }^{3,4}$ and biological methods, ${ }^{5,6}$ have been explored for the removal of VOCs, of which adsorption was regarded as the most promising method for pollution control owe to its high efficiency, low cost and ease of regeneration. $^{7-9}$ Currently, a large quantity of waste biomass is generated from both living and industrial activities, which accounts for about $62.1 \%$ of the total amount of solid waste produced each year in China. ${ }^{\mathbf{1 0}}$ Among them, plant-based

${ }^{a}$ College of Architecture and Environment, Sichuan University, Chengdu 610065, China.E-mail:xjiang@scu.edu.cn

${ }^{b}$ National Engineering Research Centre for Flue Gas Desulfurization, Chengdu 610065, China

'Department of Chemical Engineering \& Applied Chemistry, University of Toronto, 200 College St., Toronto, Ontario M5S 3E5, Canada

$\dagger$ Electronic supplementary information (ESI) available: Fig. S1 presented the schematic of the fixed bed system for toluene adsorption. Fig. S2 exhibits the yields of prepared carbon. Fig. S3 shows the SEM images of C-600, and AP-600. Fig. S4 and S5 respectively displays the $\mathrm{N}_{2}$ adsorption isotherms and pore size distribution of the prepared carbon. Fig. S6-S8 respectively presents the high resolution XPS spectra for C 1s, N 1s and P 2p of the prepared carbon. Fig. S9 shows the TG analysis of pristine stillage, mixture of tillage and APP and UP. Table S1 summarized the characteristics of nitrogen-containing phosphates. And Table S2 presents the bulk density of prepared carbon. See DOI: 10.1039/c8ra05714a biomass (PBB) is considered as the most promising carbon precursor for the preparation of biochar, because of its relatively high carbon content (>35\%), high volatiles content (55$80.4 \%$ ), abundant functional groups, low ash content, extensive source and low cost. ${ }^{\mathbf{1 1}, 12}$ Biochar is a kind of suitable adsorbent for the control of pollutants as it possesses an abundant pore structure and surface functional groups..$^{\mathbf{1 3 4}}$

Biochar from PBB is generally prepared through chemical activation methods, in which $\mathrm{KOH}$ is the most common activation agent reported in previous studies..$^{\mathbf{1 2 , 1 5 , 1 6}}$ It can help to form pores via its reactions with the carbon substrate and the resultant biochar usually possessed a high specific surface area $\left(S_{\mathrm{BET}}\right){ }^{12,17}$ However, the carbon yield from PBB using $\mathrm{KOH}$ as the activation agent was very low (10-20\%), ${ }^{12,15,17}$ and strong base of $\mathrm{KOH}$ has a serious corrosion on instruments and safety problem, which inhibited greatly the wide application of the basic agents. ${ }^{18}$

Moreover, it has been reported that the surface functionalization with some heteroatoms such as $\mathrm{N}$ atoms could change significantly the surface chemical properties of porous carbon, which could enhance its adsorption performance and catalytic activity for some specific pollutants, like VOCs, $\mathrm{CO}_{2}$ and $\mathrm{SO}_{2}$, etc. ${ }^{15,19-24}$ Generally, the post-treatment method has been widely investigated for $\mathrm{N}$-doped biochar with nitrogencontaining agents, like urea, melamine and $\mathrm{NH}_{3}$, etc. ${ }^{25}$ However, the low $\mathrm{N}$-doping content, high corrosivity, complex technical process and high consumption severely inhibited its practical application. ${ }^{25}$ Thus, it is significantly important to 


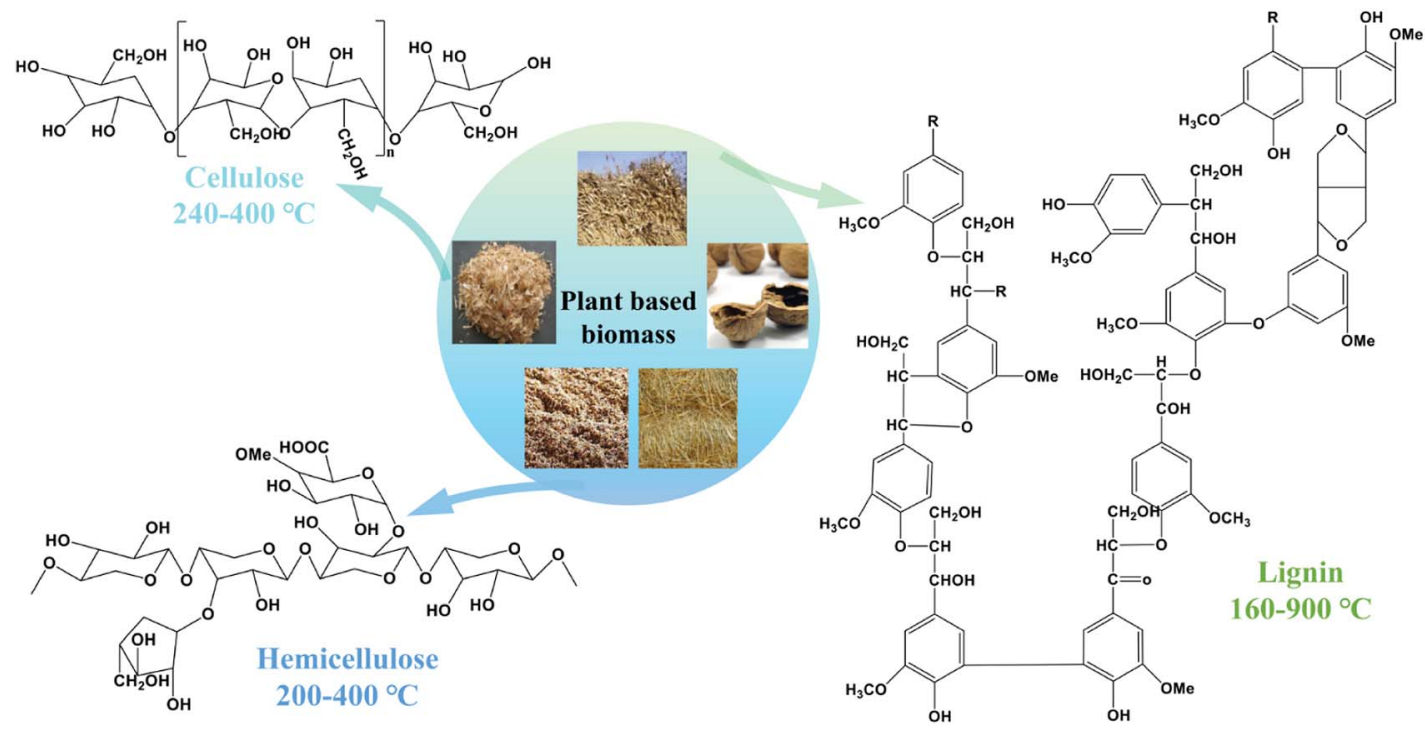

Fig. 1 The typical structure of lignocellulose in PBB and their relevant decomposition temperature. ${ }^{12}$

develop a simple and effective method to prepare the N-doped biochar with low cost, together with high yield.

Nitrogen-containing phosphates (NCPs) might be a kind of promising additive for the preparation of $\mathrm{N}$-doped biochar. First, NCPs can gradually generate $\mathrm{H}_{3} \mathrm{PO}_{4}$ during the heating process, which could help the dehydration and crosslinking of biopolymers like cellulose, hemicellulose and lignin in PBB (Fig. 1) ${ }^{12}$ with the decrease of burn off, resulting in high yield of resultant biochar. Meanwhile, the generated $\mathrm{H}_{3} \mathrm{PO}_{4}$ can react with carbon to form pores during heating process. ${ }^{26}$ On the other hand, the NCPs with high content of nitrogen can also be progressively decomposed to escape nitrogen species during the heating process, which can react with the carbon substances to form nitrogen-containing functional groups. Thus, based on the characteristics of PBB and NCPs, the NCPs exhibited a great potential as a novel additive for the preparation of biochar with high yield, abundant pores and nitrogen-containing functional groups. However, few studies have been found on using the NCPs as the additives for the preparation of biochar, and the effects of the NCPs addition on the pyrolysis process of PBB is not clear yet.

Therefore, in this study, three kinds of NCPs with different $\mathrm{P}$ contents and $\mathrm{N}$ formation were used as the additives for the preparation of biochar, including ammonia phosphate (AP), ammonia polyphosphate (APP) and urea phosphate (UP). Stillage, a common waste PBB generated from the winemaking process, was adopted as the carbon precursor. The effects of NCPs addition on the yield, pore structure and surface chemistry of the prepared biochar were investigated. Moreover, the possible interactions between NCPs and PBB was proposed to explore the preparation process of $\mathrm{N}$-doped biochar. Finally, the toluene adsorption behaviours of the prepared biochar were evaluated.

\section{Experiment}

\section{Materials}

Stillage used in this study was obtained from a local winery, Sichuan, China, whose main elemental contents were as follows (\%): C 58.72, H 7.41, O 30.49 and N 3.38. Three kinds of NCPs, including AP, APP and UP were purchased from Chengdu Kelong Chemical Factory, whose properties are tabulated in Table S1.†

\section{Preparation of biochar}

After drying at $105^{\circ} \mathrm{C}$ for $8 \mathrm{~h}$, stillage was ground and sieved to particle size below 200 mesh, and then mixed with each NCP by a pulverizer at a weight ratio of $1: 1$. The pyrolysis of the mixture was performed in a tubular furnace under $\mathrm{N}_{2}$ flow with a heating rate of $10{ }^{\circ} \mathrm{C} \mathrm{min}^{-1}$ to the target temperature and maintained for $1 \mathrm{~h}$. After pyrolysis, the obtained carbon was washed with diluted $\mathrm{HCl}\left(1.2 \mathrm{~mol} \mathrm{~L}^{-1}\right)$ at a ratio of $1 \mathrm{~g}$ carbon/ $10 \mathrm{~mL} \mathrm{HCl}$, followed by an extensively washing by hot distilled water until a neutral $\mathrm{pH}$ of washing liquor. The required biochar could be finally obtained after drying, which was denoted as $\mathrm{AP} / \mathrm{APP} / \mathrm{UP}-x$, where $x$ represented its pyrolysis temperature $\left({ }^{\circ} \mathrm{C}\right)$.

\section{Characterization}

The pore structure of the prepared carbon was studied by $\mathrm{N}_{2}$ adsorption-desorption method using a surface area analyser (ASAP 2460, Micromeritics, USA) at 77 K. Prior to measurement, the samples were outgassed under vacuum at $250{ }^{\circ} \mathrm{C}$ for $8 \mathrm{~h}$. Their $S_{\text {BET }}$ was calculated from their isotherms data with the relative pressure ranging from 0.01 to 0.3 . The micropore volume $\left(V_{\text {mic }}\right)$ and total pore volume $\left(V_{\text {tot }}\right)$ were derived from the $\mathrm{N}_{2}$ uptake when the relative pressure was at 0.1 and 0.95 , 
respectively. The mesopore volume $\left(V_{\text {meso }}\right)$ was calculated from $\mathrm{BJH}$ model, while the micropore size distribution was obtained by using DFT model.

The chemical composition of the prepared carbon was determined by X-ray photoelectron spectroscopy (ESCALAB250, Thermo, USA) with Al K $\alpha$ X-rays radiation. The high resolution XPS spectra for each element was measured at a $0.2 \mathrm{eV}$ step size and their signals were fitted using mixed Lorentzian-Gaussian curves with a Shirley function as background. Fourier transform infrared (FTIR) spectra was obtained on a spectrometer (Nicolet 6700 , Thermo, USA) in the wave number in the ranging of 4000$400 \mathrm{~cm}^{-1}$.

The pyrolysis process of stillage, AP and their mixture were investigated via TG-FTIR method with following protocol. Samples were loaded in a platinum pan of the TG analyzer (TG $209 \mathrm{C}$, NETZSCH, Germany) and heated with a heating rate of $10{ }^{\circ} \mathrm{C} \mathrm{min}{ }^{-1}$ from room temperature to $1000{ }^{\circ} \mathrm{C}$ under $\mathrm{N}_{2}$ atmosphere. The generated gas was recorded every 15 seconds by an FTIR analyser (Tensor 27, Bruker, Germany) with a resolution of $2 \mathrm{~cm}^{-1}$.

\section{Toluene adsorption test}

The toluene adsorption behavior of the prepared biochar was estimated by a fixed bed reactor system, whose schematic is depicted in Fig. S1. $\dagger$ Two lines of $\mathrm{N}_{2}$ gas was controlled by two mass flow meters, respectively, in which one was bubbled through a pure toluene solution to bring out the toluene vapor and the other line was adopted as the balance gas to make the inlet toluene concentration maintained at $600 \mathrm{ppmv}$ and the total flow rate of gas at $400 \mathrm{~mL} \mathrm{~min}^{-1}$. The prepared biochar was filled into a glass-made fixed bed (inner diameter: $10 \mathrm{~mm}$ ), with the packing height at $20 \mathrm{~mm}$. The reaction temperature was controlled at $30{ }^{\circ} \mathrm{C}$ and the outlet content of toluene was online monitored every $10 \mathrm{~min}$ by a GC-FID (Agilent, 7892B, USA) analyzer equipped with a six-way valve. The toluene adsorption capacity was calculated from the integration of the breakthrough curve.

\section{Results and discussion}

\section{Yield of biochar}

Fig. $\mathrm{S} 2 \uparrow$ shows the yields of prepared biochar obtained with different NCPs (AP, APP and UP) and at different temperature (500-900 ${ }^{\circ} \mathrm{C}$ ). The yields of the biochar from pristine stillage were in the range of 26.5-31.5 and slightly decreased with the increase of pyrolysis temperature. Compared with the pristine stillage, the yields of the NCPs-treated biochar was evidently higher with the temperature range from 500 to $800{ }^{\circ} \mathrm{C}$ (over $45 \%$ ), demonstrating that the addition of NCPs could effectively increase the yield of biochar. When the pyrolysis temperature was raised to $900{ }^{\circ} \mathrm{C}$, the yields of all the NCPs-treated biochar decreased dramatically and were close to the blank sample.

\section{Characterization of biochar}

Pore structure. The SEM images of the blank biochar and the NCPs- treated biochar (i.e. C-600 and AP-600) are presented in
Fig. S3. $\dagger$ It can be seen that the fiber structure of pristine stillage was still remained for blank biochar and its surface was relatively smooth. The morphology of AP-600 was quite different, and the fiber structure of stillage was evidently damaged and much more pores could be found on the surface of AP-600. This suggests that the addition of AP greatly changed the surface morphology and improved the porous structure of biochar.

The $\mathrm{N}_{2}$ adsorption-desorption isotherms of the prepared biochar is plotted in Fig. S4. $\dagger$ It can be seen that a small amount of $\mathrm{N}_{2}$ could be adsorbed by blank biochar (i.e. C-600 and C-900) during the whole relative pressure, while all the biochar with the addition of NCPs presented significantly higher $\mathrm{N}_{2}$ adsorption capacities. For the samples prepared at $600{ }^{\circ} \mathrm{C}$, the NCPs-treated biochar presented evidently higher $\mathrm{N}_{2}$ adsorption uptake (from 100 to $150 \mathrm{~cm}^{3} \mathrm{~g}^{-1}$ ) at low relative pressure, suggesting that the NCPs-treated biochar had abundant micropores. Furthermore, the isotherm of the biochar with NCPs presented distinct hysteresis loops, demonstrating the existence of some mesopores in the biochar. The NCPs-treated biochar prepared at $900{ }^{\circ} \mathrm{C}$ exhibited evidently better $\mathrm{N}_{2}$ adsorption performance at low relative pressure and more evident hysteresis loops, compared with those at $600{ }^{\circ} \mathrm{C}$. This indicates that more micropores and mesopores could be generated at high temperature.

The textural properties of the samples calculated from the $\mathrm{N}_{2}$ adsorption isotherms are summarized in Table 1 . The blank biochar (i.e. C-600 and C-900) had very low $S_{\mathrm{BET}}$ and $V_{\text {tot }}$, at about $40 \mathrm{~m}^{2} \mathrm{~g}^{-1}$ and $0.08 \mathrm{~cm}^{3} \mathrm{~g}^{-1}$, respectively, demonstrating their poor pore structure. After the addition of NCPs, the $S_{\mathrm{BET}}$, $V_{\text {tot }}$ and $V_{\text {mic }}$ of the NCPs-treated biochar were dramatically increased. For the samples prepared at $600{ }^{\circ} \mathrm{C}$, their $S_{\mathrm{BET}}$ and $V_{\text {tot }}$ were at $388-481 \mathrm{~m}^{2} \mathrm{~g}^{-1}$ and $0.265-0.303 \mathrm{~cm}^{3} \mathrm{~g}^{-1}$, respectively, and the $V_{\text {mic }} / V_{\text {tot }}$ ratios were in the range of $59.2-69.4 \%$, with the highest for AP-600, indicating that AP might help to generate more micropores. Compared with the samples prepared at $600{ }^{\circ} \mathrm{C}$, all the biochar prepared at $900{ }^{\circ} \mathrm{C}$ presented higher $S_{\mathrm{BET}}, V_{\text {tot }}, V_{\text {meso }}$ and $V_{\text {mic }}$, especially for $V_{\text {meso }}$, while the $V_{\text {mic }} / V_{\text {tot }}$ ratios were lower in the range of $45.5-50.9 \%$, indicating that high temperature helps to develop mesopores.

The pore size distribution of the prepared biochar is presented in Fig. S5. $\dagger$ Little pores with the diameter lower than $3 \mathrm{~nm}$ could be found in the C-600, while all the biochar with the NCPs exhibited several evident peaks and the peak located at

Table 1 Textural properties of prepared biochar

\begin{tabular}{lrllll}
\hline & & \multicolumn{2}{l}{ Pore volume $\left(\mathrm{cm}^{3} \mathrm{~g}^{-1}\right)$} & \\
\cline { 3 - 5 } Sample & $S_{\text {BET }}\left(\mathrm{m}^{2} \mathrm{~g}^{-1}\right)$ & $V_{\text {tot }}$ & $V_{\text {mic }}$ & $V_{\text {meso }}$ & $V_{\text {mic }} / V_{\text {tot }}(\%)$ \\
\hline C-600 & 37 & 0.073 & 0.017 & 0.056 & 23.3 \\
AP-600 & 481 & 0.291 & 0.202 & 0.087 & 69.4 \\
APP-600 & 388 & 0.265 & 0.157 & 0.108 & 59.2 \\
UP-600 & 443 & 0.303 & 0.182 & 0.119 & 60.0 \\
C-900 & 40 & 0.081 & 0.018 & 0.063 & 22.2 \\
AP-900 & 798 & 0.464 & 0.211 & 0.253 & 45.5 \\
APP-900 & 831 & 0.468 & 0.223 & 0.245 & 47.6 \\
UP-900 & 666 & 0.428 & 0.218 & 0.210 & 50.9
\end{tabular}


0.6-0.7 $\mathrm{nm}$ presented the highest intensity. Such micropores are beneficial for the adsorption of pollutants with small sizes, like $\mathrm{CO}_{2}, \mathrm{SO}_{2}$, and $\mathrm{H}_{2} \mathrm{~S}$ etc. ${ }^{15,20,24}$ On the other hand, the peak located at 1.0-2.0 $\mathrm{nm}$ for all the NCPs prepared biochar at $900{ }^{\circ} \mathrm{C}$ presented higher intensity than those at $600{ }^{\circ} \mathrm{C}$, indicating that high temperature helps the formation of more micropores with larger size. The biochar prepared in our study was different from that prepared by $\mathrm{H}_{3} \mathrm{PO}_{4}$, which was likely with more mesopores ${ }^{\mathbf{2 6}}$. This suggests that the biochar treated with NCPs might be preferred for preparing the adsorbates with more micropores.

Elemental analysis. The elemental contents of prepared biochar obtained from XPS analysis are listed in Table 2. The blank biochar (C-600) exhibited evidently higher $\mathrm{C}$ content (82.81\%), compared with NCPs-treated biochar prepared at $600{ }^{\circ} \mathrm{C}$ (70.78-73.61\%), indicating that more non-carbon substances were introduced on the carbon surface with the addition of NCP. Furthermore, the NCP-treated biochar exhibited distinctively higher $\mathrm{N}$ contents (3.26-4.16\%) than $\mathrm{C}$ $600(1.54 \%)$, suggesting that $\mathrm{N}$ atoms were successfully doped by the addition of NCP.

For the samples prepared at $900{ }^{\circ} \mathrm{C}$, their carbon contents were approximately similar, i.e. about $79 \%$, and the relative contents of $\mathrm{C}$ in all NCP-treated biochar were dramatically increased, compared with those at $600{ }^{\circ} \mathrm{C}$. This indicates that more non-carbon species were released at high temperature. Both $\mathrm{N}$ and $\mathrm{P}$ contents dramatically decreased, compared with those prepared at $600{ }^{\circ} \mathrm{C}$, suggesting that part of $\mathrm{N}$ and $\mathrm{P}$ species with lower thermal stability was decomposed. However, the $\mathrm{N}$ and $\mathrm{P}$ contents of the NCP-treated biochar were higher than those of C-900, indicating that some $\mathrm{N}$ and $\mathrm{P}$ species still maintained on the surface of carbon after high temperature, which might be existed in more stable forms. In addition, APtreated biochar had relatively higher contents of $\mathrm{N}$ than the other samples, possibly due to higher contents of $\mathrm{N}$ existed in AP (Table S1 $\dagger$ ).

Surface functional groups. The FTIR spectra of the prepared biochar are plotted in Fig. 2. The broad band located at 3000$3500 \mathrm{~cm}^{-1}$ and the peak at about $1580 \mathrm{~cm}^{-1}$ could be found in all prepared samples, which are attributed to the secondary amines and $\mathrm{C}=\mathrm{O}$, respectively. ${ }^{27}$ The $\mathrm{C}-600$ had the signal appearing at $1091 \mathrm{~cm}^{-1}$ that was ascribed to the tertiary amines, ${ }^{28}$ which might be derived from the $\mathrm{N}$ atoms existing in pristine stillage, while the NCP-treated biochar didn't show this peak, which might be due to the interference from other species
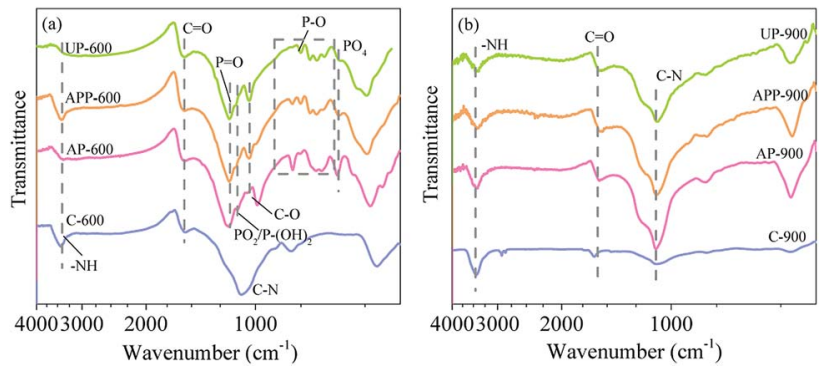

Fig. 2 FTIR spectra of prepared biochar at $600{ }^{\circ} \mathrm{C}$ (a) and $900{ }^{\circ} \mathrm{C}$ (b).

in the samples, such as P species. AP-600, APP-600 and UP-600 presented approximately same bands at 1190, 1100, 1040 and $597 \mathrm{~cm}^{-1}$, which were assigned to the stretching vibration of hydrogen-bonded $\mathrm{P}=\mathrm{O}$ groups of phosphates, ${ }^{26}$ symmetric stretching vibration of $\mathrm{PO}_{2}$ or the asymmetric stretching vibration of $\mathrm{P}-(\mathrm{OH})_{2}$ in phosphate, stretching vibration of the $\mathrm{C}-\mathrm{O}$ in $\mathrm{P}-\mathrm{O}-\mathrm{R}$ and the asymmetric deformation vibration of $\mathrm{PO}_{4}$ in phosphate, respectively. Furthermore, a series of peaks located at $1000-750 \mathrm{~cm}^{-1}$ were due to the asymmetric stretching vibrations of $\mathrm{C}-\mathrm{O}-\mathrm{P}$ and $\mathrm{P}-\mathrm{O}-\mathrm{P} .{ }^{29}$ All the bands are the characteristics of the presence of phosphorus compounds like phosphate, polyphosphate and phosphate esters in the prepared biochar due to the addition of NCPs.

For the samples prepared at $900{ }^{\circ} \mathrm{C}$, much less functional groups could be detected compared with those at $600{ }^{\circ} \mathrm{C}$. Only the peaks ascribed to $\mathrm{NH}, \mathrm{C}=\mathrm{O}$ and $\mathrm{C}-\mathrm{N}$ presented, indicating that some $\mathrm{N}$ species were remained on the surface of carbon. However, the bands belonging to $\mathrm{P}$ species were in absence, indicating that most of the phosphorus compounds were decomposed or the $\mathrm{P}$ species existing on the carbon surface might be in non-IR active, like elemental $\mathrm{P}$, etc.

The relative contents of each functional group obtained from the high resolution XPS spectra (Fig. S6-S8†) are given in Table 3. It could be seen that four kinds of functional groups could be detected in $\mathrm{C}$ 1s spectra in all samples, i.e. $\mathrm{C}-\mathrm{C}, \mathrm{C}-\mathrm{O}, \mathrm{C}=\mathrm{O}$ and COOR..$^{30}$ It can be seen that for the samples prepared at $600{ }^{\circ} \mathrm{C}$, NCPs-treated biochar presented similar contents of $\mathrm{C}-\mathrm{O}$ and $\mathrm{C}=\mathrm{O}$, while evidently higher COOR content (10.47-19.82\%), compared with blank biochar $(5.11 \%)$. This demonstrates that more esters were generated in the carbon with NCPs addition. For the samples prepared at $900{ }^{\circ} \mathrm{C}$, the contents of esters and $\mathrm{C}=\mathrm{O}$ dramatically decreased $(<5 \%)$, indicating that they were decomposed at higher temperature. Based on the FTIR analysis

Table 2 Elemental analysis of prepared biochar

\begin{tabular}{|c|c|c|c|c|c|c|}
\hline Sample & C 1s (\%) & O 1s (\%) & N 1s (\%) & P 2p (\%) & $\mathrm{O} 1 \mathrm{~s} / \mathrm{C} 1 \mathrm{~s}$ & $\mathrm{~N} 1 \mathrm{~s} / \mathrm{C} 1 \mathrm{~s}$ \\
\hline C-600 & 82.81 & 15.43 & 1.54 & 0.22 & 0.186 & 0.019 \\
\hline AP-600 & 73.61 & 19.66 & 4.16 & 2.58 & 0.267 & 0.057 \\
\hline APP-600 & 75.08 & 19.17 & 3.45 & 2.30 & 0.255 & 0.046 \\
\hline UP-600 & 70.78 & 23.56 & 3.26 & 2.39 & 0.333 & 0.046 \\
\hline C-900 & 79.91 & 19.46 & 0.47 & 0.16 & 0.244 & 0.005 \\
\hline AP-900 & 79.31 & 18.01 & 1.60 & 0.88 & 0.227 & 0.023 \\
\hline APP-900 & 79.79 & 17.82 & 1.54 & 0.85 & 0.223 & 0.019 \\
\hline UP-900 & 78.13 & 20.61 & 0.76 & 0.50 & 0.263 & 0.010 \\
\hline
\end{tabular}


Table 3 Relative contents of functional groups in prepared biochar calculated from XPS spectra

\begin{tabular}{|c|c|c|c|c|c|c|c|c|}
\hline Sample & $600-C$ & 600-AP & 600-APP & 600-UP & $900-\mathrm{C}$ & 900-AP & 900-APP & 900-UP \\
\hline $\mathrm{C}-\mathrm{C}$ & 64.23 & 54.89 & 61.63 & 44.60 & 77.19 & 67.28 & 64.24 & 71.88 \\
\hline $\mathrm{C}-\mathrm{O}$ & 18.98 & 20.30 & 18.60 & 23.86 & 14.04 & 24.17 & 27.15 & 19.13 \\
\hline $\mathrm{C}=\mathrm{O}$ & 11.68 & 10.53 & 9.30 & 9.85 & 3.86 & 4.48 & 3.66 & 6.68 \\
\hline COOR & 5.11 & 14.29 & 10.47 & 19.82 & 4.91 & 4.68 & 4.94 & 2.29 \\
\hline Pyridinic & 28.57 & 30.29 & 47.25 & 29.45 & - & 28.13 & 12.99 & 21.05 \\
\hline Pyrrolic & 47.40 & 47.36 & 35.65 & 70.55 & & 25.00 & 22.08 & 30.26 \\
\hline Graphitic & 14.94 & 18.03 & 9.28 & - & & 26.88 & 35.06 & 38.16 \\
\hline Oxidized & 9.09 & 4.33 & 7.83 & - & & 20.00 & 29.87 & 10.53 \\
\hline $\mathrm{P}$ & - & - & - & - & - & 26.14 & 16.47 & 48.00 \\
\hline $\mathrm{PO}_{4}^{3-}$ & & 33.72 & 51.30 & 22.33 & & 73.86 & 83.53 & 52.00 \\
\hline $\mathrm{PO}_{3}^{-}$ & & - & 11.30 & 7.57 & & - & - & - \\
\hline $\mathrm{P}_{2} \mathrm{O}_{5}$ & & 66.28 & 37.39 & 70.10 & & - & - & - \\
\hline
\end{tabular}

(Fig. 2), it can be assumed that the esters might be phosphorus esters.

As shown in Table 3, all samples prepared at $600{ }^{\circ} \mathrm{C}$ had four kinds of $\mathrm{N}$ species, including pyridinic $\mathrm{N}$, pyrrolic $\mathrm{N}$, graphitic $\mathrm{N}$ and oxidized $\mathrm{N} .{ }^{31}$ It can be seen that pyridinic $\mathrm{N}$ and pyrrolic $\mathrm{N}$ were the main forms of $\mathrm{N}$ atoms. However, for the samples prepared at $900{ }^{\circ} \mathrm{C}$, the relative contents of pyridinic $\mathrm{N}$ and pyrrolic $\mathrm{N}$ decreased significantly, while the contents of graphitic $\mathrm{N}$ and oxidized $\mathrm{N}$ increased evidently. This indicates that more $\mathrm{N}$ species were transferred into the inner of graphitic structure and some $\mathrm{N}$ groups were oxidized at higher temperature. ${ }^{32}$ In this study, the oxidants might be the generated gases during biomass decomposition process, like $\mathrm{CO}_{2}$ and $\mathrm{H}_{2} \mathrm{O}$, etc. This result is corresponded to previous studies that used $\mathrm{NH}_{3}$ post heating treatment for carbon surface modification..$^{32}$ They reported that much more graphitic $\mathrm{N}$ and oxidized $\mathrm{N}$ were generated with high temperature (i.e. $800^{\circ} \mathrm{C}$ ). It can be assumed that the NCPs can be decomposed into $\mathrm{NH}_{3}$, which could modify the carbon surface during pyrolysis process.

XPS results show that the $\mathrm{P} 2 \mathrm{p}$ peaks for blank biochar (C-600 and $\mathrm{C}-900)$ were not detected, due to the low content of $\mathrm{P}$ in pristine stillage, while the resolution of the NCPs-treated biochar was evident. As shown in Table 3, all NCPs-treated biochar prepared at $600{ }^{\circ} \mathrm{C}$ had the peaks ascribed to $\mathrm{PO}_{4}{ }^{3-}$ and $\mathrm{P}_{2} \mathrm{O}_{5},{ }^{33}$ which might be the $\mathrm{H}_{3} \mathrm{PO}_{4}$ generated from the NCPs or/and derived from the partial decomposition of phosphate esters (Fig. 2). Furthermore, the APP-600 and UP-600 showed a small amount of $\mathrm{P}$ existing as the form of $\mathrm{PO}_{3}{ }^{-},{ }^{33}$ which might be also generated from the decomposition of phosphate compounds. When the temperature increased to $900{ }^{\circ} \mathrm{C}$, both $\mathrm{P}_{2} \mathrm{O}_{5}$ and $\mathrm{PO}_{3}{ }^{-}$ on the carbon surface were diminished, while the peak ascribing to elemental $\mathrm{P}$ appeared. ${ }^{33}$ This indicates that these phosphorus oxides were reduced by carbon to elemental $\mathrm{P}$ under high temperature. ${ }^{34}$

The results of both FTIR and XPS analysis demonstrated that $\mathrm{N}$ heteroatoms could be successfully introduced to the surface of the biochar with the treatment of NCPs, which was quite different with those prepared from conventional additives, like $\mathrm{H}_{3} \mathrm{PO}_{4}$ and $\mathrm{KOH}$. On the one hand, when $\mathrm{H}_{3} \mathrm{PO}_{4}$ or $\mathrm{KOH}$ were used for the additives, post treatment is necessary for the introduction of $\mathrm{N}$ to the carbon surface, ${ }^{35}$ while the NCPs used in our study presented a high content of $\mathrm{N}$ (Table $\mathrm{S} 1 \dagger$ ), which could provide abundant $\mathrm{N}$ atoms with resultant biochar. On the other hand, the conventional additives could release $\mathrm{N}$ atoms that existed in biomass, especially for $\mathrm{KOH}$, which caused a further decrease of $\mathrm{N}$ content in resultant biochar. ${ }^{36}$

\section{TG-FTIR analysis during pyrolysis process}

TG analysis. As shown in Fig. 3, the TG curve of the mixture of stillage and AP with the weight ratio of $1: 1$ were also plotted, together with the simulated curve calculated from the respective TG curves of stillage and AP. It can be seen that the two TG curves were not coincided, indicating that there were some interactions happened between stillage and AP during the pyrolysis process. From $100{ }^{\circ} \mathrm{C}$ to $340{ }^{\circ} \mathrm{C}$, the mixture presented a higher weight loss compared with the fitting curve, indicating that the addition of AP might help the decomposition of stillage or vice versa. With the temperature growing from 340 to $600{ }^{\circ} \mathrm{C}$, the weight loss of the mixture was clearly lower than that of fitting curve, suggesting that more substances remained on the surface of carbon. According to both FTIR (Fig. 2) and XPS analysis (Table 3), we can find that some phosphate esters existing on the surface of carbon after the pyrolysis of the mixture at $600{ }^{\circ} \mathrm{C}$. This suggests that the NCPs could be

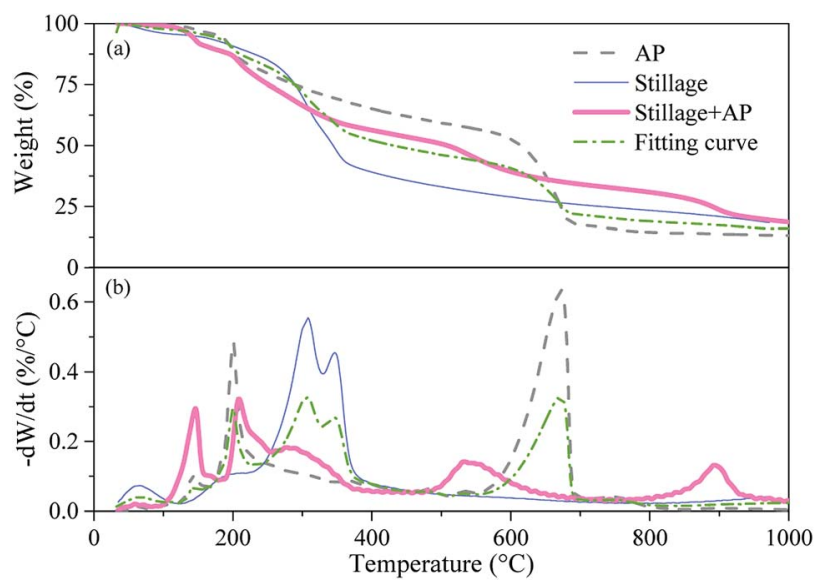

Fig. 3 TG (a) and DTG (b) analysis of AP, pristine stillage and their mixture with the weight ratio of $1: 1$. 
decomposed to $\mathrm{H}_{3} \mathrm{PO}_{4}$ firstly, which subsequently react with the lignocellulose in biomass to form phosphate esters to inhibit the decomposition of carbon substances and decrease the weight loss of biomass. ${ }^{12}$ As a result, the biochar yields were higher for the samples with the NCPs, compared with blank biochar (Fig. S1 $\dagger$ ). Notably, an evident weight loss of the mixture could be observed from $500{ }^{\circ} \mathrm{C}$, with the DTG peak at about $537{ }^{\circ} \mathrm{C}$, while the fitting curve was at about $672{ }^{\circ} \mathrm{C}$. This phenomenon might indicate that the generated phosphorus esters started to decompose from $500{ }^{\circ} \mathrm{C},{ }^{33}$ resulting in the appearance of $\mathrm{P}_{2} \mathrm{O}_{5}$ on the surface of AP-600 (Table 3). Finally, a distinct decomposition peak was detected for the mixture from $800{ }^{\circ} \mathrm{C}$, with the DTG peak at about $893{ }^{\circ} \mathrm{C}$, while no evident weight loss could be found in the fitting curve. As a result, the weight loss caused the decrease of yield for biochar prepared at $900{ }^{\circ} \mathrm{C}$ (Fig. $\mathrm{S} 2 \dagger$ ). As shown in Table 3, both $\mathrm{N}$ and $\mathrm{P}$ contents declined dramatically for the samples prepared at $900{ }^{\circ} \mathrm{C}$. This suggests that some reactions involving nitrogen, phosphate compounds and carbon happened within this temperature range, resulting in the change of $\mathrm{C}, \mathrm{N}$ and $\mathrm{P}$ species existing on carbon surface (Table 3).

In addition, the TG curves of the APP mixture (APP + stillage) and UP mixture (UP + stillage) were not coincided with their relevant fitting curves (Fig. $\mathrm{S} 9 \dagger$ ), either, demonstrating that the two NCPs also took part in the activation process of stillage. Furthermore, the weight loss profile of the APP mixture and UP mixture were parallel to that of AP mixture, which suggests that the reactions occurred between carbon with the APP or UP were similar to those with AP.

TG-FTIR analysis. To understand better the preparation process of biochar with AP addition, the gaseous products generated from the pyrolysis of stillage, AP and their mixture were monitored by FTIR spectrometer, along with the TG analysis, as shown in Fig. 4. In Fig. 4(a) $\left(<270{ }^{\circ} \mathrm{C}\right)$, for stillage, when the temperature were higher than $180{ }^{\circ} \mathrm{C}$, two peaks located at 1798 and $1128 \mathrm{~cm}^{-1}$ appeared, which were ascribed to the stretch vibration of $\mathrm{C}=\mathrm{O}$ in fatty groups and $\mathrm{C}-\mathrm{O}-\mathrm{C}$ in saccharides, respectively. ${ }^{12}$ This suggests that the decomposition of lignin in stillage started. ${ }^{12}$ Furthermore, the peaks at 2359 and $2338 \mathrm{~cm}^{-1}$ could also be detected when temperature were higher than $210^{\circ} \mathrm{C}$, which were the $\mathrm{R}$ and $\mathrm{P}$ branches of the asymmetric stretch vibration of $\mathrm{CO}_{2}$ molecules, respectively. ${ }^{37}$ With the increase of temperature, the intensities of all the peaks got higher, indicating that the decomposition process became more vigorous.

For AP, two series of peaks could be detected when temperature was higher than $120{ }^{\circ} \mathrm{C}$, which were due to the stretch and deformation vibration of $\mathrm{NH}_{3}$, demonstrating that AP began to decompose and the $\mathrm{NH}_{3}$ molecules could be released gradually. Their intensities were increased first when temperature was lower than $210{ }^{\circ} \mathrm{C}$, and then gradually decreased.

For the spectra of the mixture, when the temperature was about $120{ }^{\circ} \mathrm{C}$, the vibration of $\mathrm{NH}_{3}$ could be detected. And the intensities of $\mathrm{NH}_{3}$ were increased when temperature were lower than $150{ }^{\circ} \mathrm{C}$, while decreased over $150{ }^{\circ} \mathrm{C}$. The phenomena were different from that of AP, indicating that the stillage might promote the decomposition of $\mathrm{AP}$ at lower temperature. In

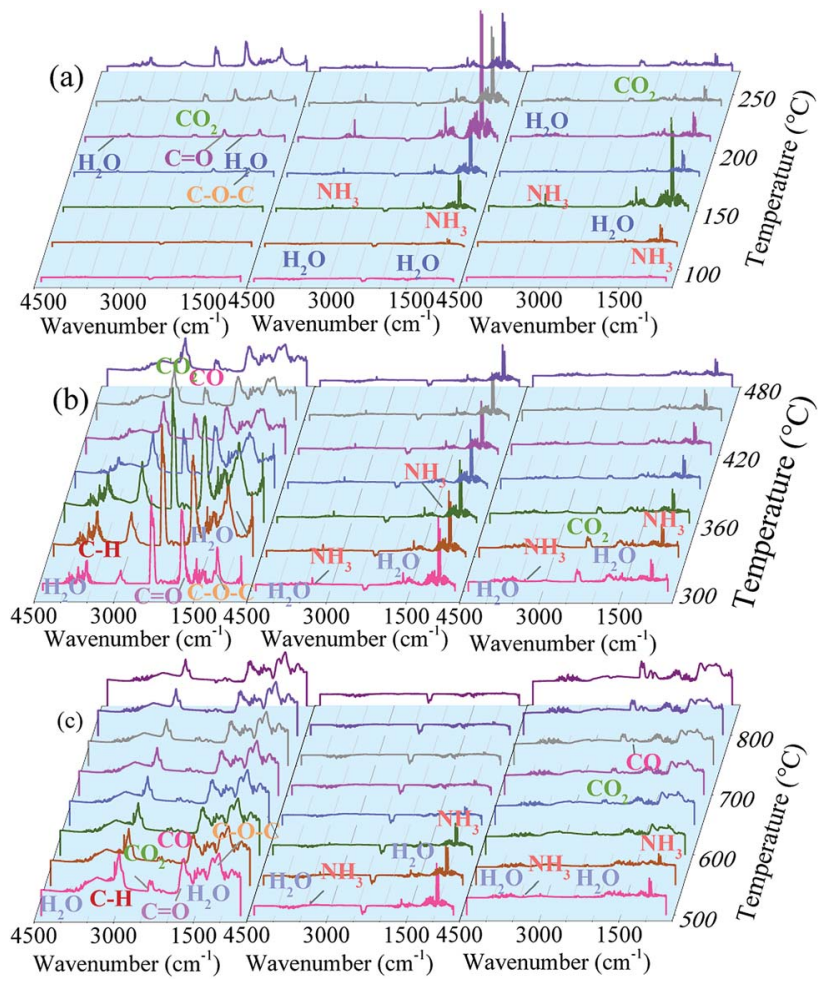

Fig. 4 Typical FTIR spectra for the gaseous products of stillage (left), AP (middle) and their mixture (right) at different temperature. (90$270{ }^{\circ} \mathrm{C}$ (a), $300-480^{\circ} \mathrm{C}$ (b), $500-850^{\circ} \mathrm{C}$ (c)).

addition, the intensities of $\mathrm{H}_{2} \mathrm{O}$ were higher in the mixture sample when temperature were higher than $120{ }^{\circ} \mathrm{C}$, suggesting that the addition of AP could help the dehydration of stillage. Meanwhile, no peaks ascribed to $\mathrm{C}=\mathrm{O}$ and $\mathrm{C}-\mathrm{O}-\mathrm{C}$ could be found in the spectra of the mixture, while only a small amount of $\mathrm{CO}_{2}$ could be detected when temperature were higher than $180{ }^{\circ} \mathrm{C}$. This suggests that the decomposition pathway of biomass was severely changed with the presence of AP. It was reported that the ethers in $\mathrm{PBB}$ could be dehydrated to ketone with the catalysis of $\mathrm{H}_{3} \mathrm{PO}_{4}$ when temperature were higher than $50{ }^{\circ} \mathrm{C}^{27}$ This suggests that the dehydration might occur for ethers in PBB once the AP was decomposed, instead of being liberated, avoiding the reduction of carbon species.

As illustrated in Fig. 4(b), from 300 to $500{ }^{\circ} \mathrm{C}$, the peaks ascribed to $\mathrm{H}_{2} \mathrm{O}, \mathrm{C}=\mathrm{O}, \mathrm{C}-\mathrm{O}-\mathrm{C}$ and $\mathrm{CO}_{2}$ could be detected in all spectra of stillage. Furthermore, the absorption bands ranging from 3030-2800 $\mathrm{cm}^{-1}$ appeared, which were assigned to the stretch vibration of $\mathrm{CH}, \mathrm{CH}_{2}$ and $\mathrm{CH}_{3}$, suggesting the generation of some light alkanes, such as methane, ethane or propane. ${ }^{37}$ The products were generated from the decomposition of hemicellulose and cellulose in stillage. ${ }^{12}$ For $\mathrm{AP}, \mathrm{H}_{2} \mathrm{O}$ and $\mathrm{NH}_{3}$ were still the main gaseous products at this temperature range, especially the $\mathrm{NH}_{3}$ was generated drastically with similar intensities. This indicates that $\mathrm{NH}_{3}$ could be released gradually from the AP during pyrolysis process. For the mixture of stillage and $\mathrm{AP}, \mathrm{H}_{2} \mathrm{O}$, $\mathrm{CO}_{2}$ and $\mathrm{NH}_{3}$ were the main products at this period. No bands belonging to the light hydrocarbons could be detected and the peak intensities of both $\mathrm{CO}_{2}$ and $\mathrm{NH}_{3}$ were relatively lower than 
those of the stillage and $\mathrm{AP}$, respectively, especially for $\mathrm{CO}_{2}$, suggesting that the loss of carbon species were suppressed.

When the temperature was higher than $500{ }^{\circ} \mathrm{C}$ (Fig. 4(c)), for the stillage, the intensity of peaks belonging to light alkanes was higher than that of $\mathrm{CO}_{2}$, and with temperature growing, less $\mathrm{CO}_{2}$ could be generated. For AP, even though the contents of generated $\mathrm{NH}_{3}$ kept decrease, there was still $\mathrm{NH}_{3}$ released below $700{ }^{\circ} \mathrm{C}$. This indicates that $\mathrm{N}$ source existed within $700{ }^{\circ} \mathrm{C}$. For the mixture, from 500 to $550{ }^{\circ} \mathrm{C}, \mathrm{H}_{2} \mathrm{O}$ and $\mathrm{NH}_{3}$ were its main products, while no more $\mathrm{NH}_{3}$ molecule could be detected and more $\mathrm{CO}_{2}$, $\mathrm{CO}$ and $\mathrm{H}_{2} \mathrm{O}$ were generated when temperature were higher than $600{ }^{\circ} \mathrm{C}$. It is possible that there are four types of processes occurred at this temperature range. First, the generated $\mathrm{NH}_{3}$ was evolved in the decomposition of stillage, which lead to the formation of N-containing groups on the surface of carbon (Table 3) and meanwhile help to develop pores. Second, the contents of $\mathrm{CO}_{2}$ and $\mathrm{C}-\mathrm{O}-\mathrm{C}$ in gas phase increased significantly after $750{ }^{\circ} \mathrm{C}$, which was corresponded with an evident weight loss in TG curve (Fig. 3). Third, the gradually increased $\mathrm{CO}$ content from $750{ }^{\circ} \mathrm{C}$ demonstrating the reactions of carbon substrate with some oxidants, like $\mathrm{CO}_{2}, \mathrm{H}_{2} \mathrm{O}$ and $\mathrm{P}_{2} \mathrm{O}_{5}$, etc. Furthermore, as shown in Table 2, the $\mathrm{P}$ contents decreased dramatically from 600 to $900{ }^{\circ} \mathrm{C}$, while no P species could be found in FTIR patterns at this temperature range (Fig. 2). It can be assumed that the elemental $\mathrm{P}$, which is in non-IR activity, was released from the reactions between $\mathrm{P}_{2} \mathrm{O}_{5}$ and carbon matrix. ${ }^{34}$ In the preparation process, we found that some red substances precipitated on the inner wall of the furnace when the pyrolysis temperature were beyond $800{ }^{\circ} \mathrm{C}$, which must be the condensed elemental $\mathrm{P}$.

\section{Possible interactions between PBB and NCP}

Based on the above results, the possible interactions between PBB and NCP during the preparation process of biochar was proposed, which could be classified into two aspects, including $\mathrm{P}$ route and $\mathrm{N}$ route, as illustrated in Fig. 5.

For $\mathrm{P}$ route, when temperature were higher than $120^{\circ} \mathrm{C}, \mathrm{AP}$ might be firstly decomposed into $\mathrm{H}_{3} \mathrm{PO}_{4}$ (eqn (1)-(3)). At lower temperature $\left(<340{ }^{\circ} \mathrm{C}\right.$ ), in the presence of $\mathrm{H}_{2} \mathrm{O}$ (Fig. 4(a)), the generated $\mathrm{H}_{3} \mathrm{PO}_{4}$ could act as a Brønsted acid to catalyze the dehydration of ethers in $\mathrm{PBB}$, like lignin, cellulose and hemicellulose, etc., into ketones and $\mathrm{H}_{2} \mathrm{O} .{ }^{38,39}$ As a result, the $\mathrm{O}$ and $\mathrm{H}$ species were volatilized and the weight loss was higher within the temperature range (Fig. 4). With temperature growing (340$500{ }^{\circ} \mathrm{C}$ ), phosphate esters (PE) were formed from the crosslinking of $\mathrm{H}_{3} \mathrm{PO}_{4}$ and biopolymers (BPs) in PBB (eqn (4)), which could keep stable during this period and avoid the escape of $\mathrm{C}$ atoms. Furthermore, when temperature was higher than $500{ }^{\circ} \mathrm{C}$, part of the generated phosphate esters started to decompose into $\mathrm{P}_{2} \mathrm{O}_{5}$ (Table 3), $\mathrm{H}_{2} \mathrm{O}$ and $\mathrm{CO}_{2}$ (Fig. 4). With temperature higher than $800{ }^{\circ} \mathrm{C}$, the generated $\mathrm{P}_{2} \mathrm{O}_{5}$ might play as an oxidant for carbon species to produce $\mathrm{CO}_{2}$ and elemental P. At the same time, the generated elemental $\mathrm{P}$ could be evaporated and diffused through the carbon layers, leading into a further pore forming.

Decomposition

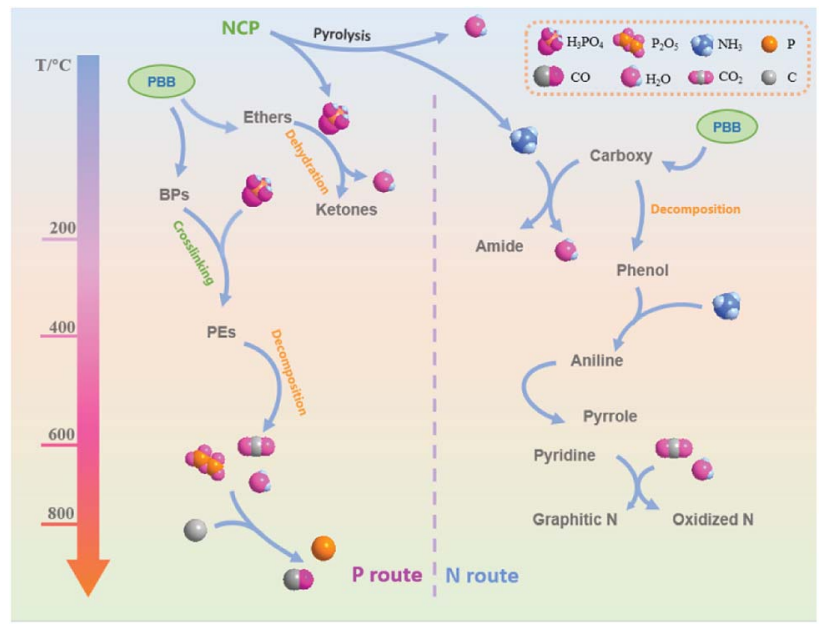

Fig. 5 Possible reactions between PBB and NCP during the pyrolysis process (PBB: plant-based biomass, NCP: nitrogen containing phosphate, BPs: biopolymers, PEs: phosphate esters).

$$
\begin{gathered}
\left(\mathrm{NH}_{4}\right)_{3} \mathrm{PO}_{4} \rightarrow\left(\mathrm{NH}_{4}\right)_{2} \mathrm{HPO}_{4}+\mathrm{NH}_{3} \uparrow \\
\left(\mathrm{NH}_{4}\right)_{2} \mathrm{HPO}_{4} \rightarrow \mathrm{NH}_{4} \mathrm{H}_{2} \mathrm{PO}_{4}+\mathrm{NH}_{3} \uparrow \\
\mathrm{NH}_{4} \mathrm{H}_{2} \mathrm{PO}_{4} \rightarrow \mathrm{H}_{3} \mathrm{PO}_{4}+\mathrm{NH}_{3} \uparrow
\end{gathered}
$$

Crosslinking

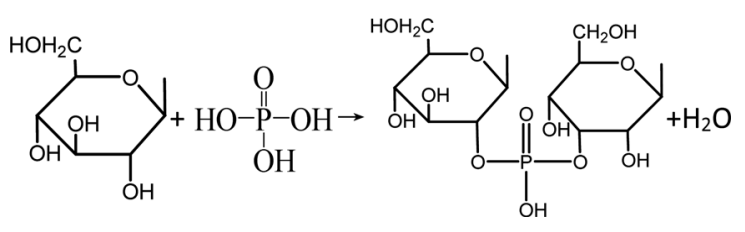

For N-route, $\mathrm{NH}_{3}$ was the main product released from the NCP during the pyrolysis process (Fig. 4). The generated $\mathrm{NH}_{3}$ could be decomposed to free radicals such as $\mathrm{NH}_{2}$ and $\mathrm{NH}$, etc., which could attack carbon substrate to form N-containing functional groups on the surface of resultant biochar (Table 3). Meanwhile, the generated $\mathrm{NH}_{3}$ could produce pores through $\mathrm{NH}_{3}$ diffusing through the carbon layers. It was reported that at lower temperature, the $\mathrm{NH}_{3}$ molecule would react with carboxy in PBB to form amide. With temperature growing (from about $300{ }^{\circ} \mathrm{C}$ ), carboxy started to be decomposed to phenolic compounds, ${ }^{40}$ resulting in the generation of anilines with the presence of $\mathrm{NH}_{3}$. When the temperature was higher (beyond 600 ${ }^{\circ} \mathrm{C}$ ), more $\mathrm{N}$ species could be transformed to the functional groups with higher thermal stability like pyridinic $\mathrm{N}$ and pyrrolic $\mathrm{N}$ (Table 3 ). Furthermore, partial $\mathrm{N}$ atoms could enter into the internal structure of carbon to form graphitic $\mathrm{N}$, or be oxidized by the generated $\mathrm{P}_{2} \mathrm{O}_{5}, \mathrm{CO}_{2}$ or/and $\mathrm{H}_{2} \mathrm{O}$ produced from the decomposition of phosphoric acid to form oxidized $\mathrm{N},{ }^{32}$ when the temperature was about $900{ }^{\circ} \mathrm{C}$ (Table 3).

Furthermore, the $\mathrm{CO}_{2}$ and $\mathrm{H}_{2} \mathrm{O}$ generated from the pyrolysis process could also act as the activators for biochar when temperature were higher than $700{ }^{\circ} \mathrm{C}$. This further created pores 
for biochar, resulting in high porous structure for the samples prepared at high temperature, i.e. $900{ }^{\circ} \mathrm{C}$ in this study (Table 1).

Furthermore, the $\mathrm{CO}_{2}$ and $\mathrm{H}_{2} \mathrm{O}$ generated from the pyrolysis process could also act as the activators for biochar when temperature were higher than $700{ }^{\circ} \mathrm{C}$. This further created pores for biochar, resulting in high porous structure for the samples prepared at high temperature, i.e. $900{ }^{\circ} \mathrm{C}$ in this study (Table 1).

\section{Toluene adsorption}

The breakthrough curve, along with the adsorption capacity, of toluene by prepared biochar is shown in Fig. 6. Blank biochar (C-600 and C-900) presented poor toluene adsorption performance, with the adsorption capacity at 6.5 and $8.0 \mathrm{mg} \mathrm{g}^{-1}$, respectively. Compared with C-600 and C-900, the samples with NCPs addition took much longer time to approach breakthrough and exhibited higher adsorption capacities. For the biochar prepared at $600{ }^{\circ} \mathrm{C}$, its breakthrough time of the NCPtreated biochar was in the order of AP-600 > UP-600 > APP600 , with their corresponding volumetric adsorption capacities as $144.0,104.0$ and $89.8 \mathrm{~g} \mathrm{~L}^{-1}$, respectively and mass adsorption capacity at $296.4,175.9$ and $245.8 \mathrm{mg} \mathrm{g}^{-1}$, respectively. The biochar prepared at $900{ }^{\circ} \mathrm{C}$ presented higher toluene uptake compared with those at $600{ }^{\circ} \mathrm{C}$, with volumetric adsorption capacities ranging from 122.5 to $164.5 \mathrm{~g} \mathrm{~L}^{-1}$ and mass adsorption capacities ranging from 364.1 to $496.2 \mathrm{mg} \mathrm{g}^{-1}$. Notably, it can be seen that AP-treated biochar presented higher mass adsorption capacity, while UP-treated biochar showed higher volumetric adsorption capacity. This might be ascribed to their different bulk density and UP had higher bulk density than AP (Table S2 $\dagger$ ).

The results show that the toluene adsorption capacity of AP900 (496.2 $\mathrm{mg} \mathrm{g}^{-1}$ ) was markedly higher than those biochar reported in previous studies using biomass as carbon precursors. ${ }^{\mathbf{4 1 , 4 2}}$ Martinez de Yuso, et al. ${ }^{\mathbf{4 2}}$ reported that the highest toluene uptake was $2.75 \mathrm{mmol} \mathrm{L}^{-1}$ (i.e. $25.3 \mathrm{mg} \mathrm{g}^{-1}$ ) for almond shell based activated carbon with $S_{\mathrm{BET}}$ at $1128 \mathrm{~m}^{2} \mathrm{~g}^{-1}$ and microporosity at $77.8 \%$. Lillo-Ródenas et $a .^{41}$ found that wood based carbon using $\mathrm{H}_{3} \mathrm{PO}_{4}$ as activation agent had the highest toluene uptake at $310 \mathrm{mg} \mathrm{g}^{-1}$, with $S_{\text {BET }}$ at $1757 \mathrm{~m}^{2} \mathrm{~g}^{-1}$. This demonstrated that the carbons prepared with NCPs in our study are desirable for toluene adsorption. Moreover, pore structure is

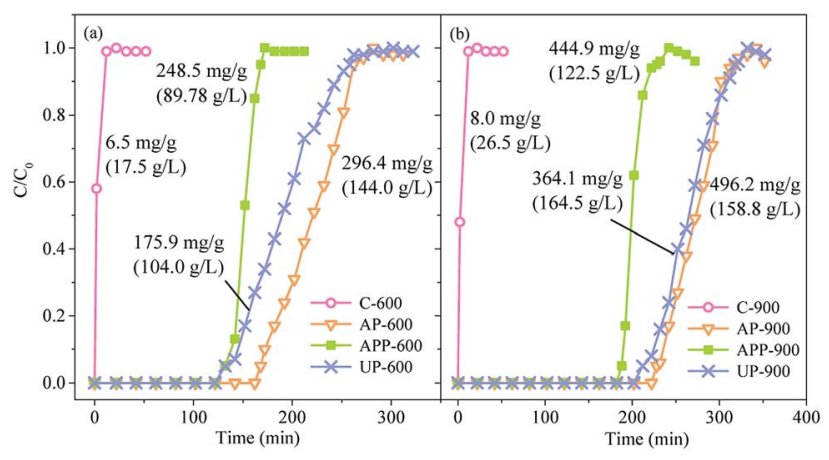

Fig. 6 The breakthrough curves of toluene by prepared biochar. (The numbers labelled beside the curve represented the toluene adsorption capacity of the relevant carbon). not the only one factor contributing to such excellent adsorption behavior.

As shown in Table 3, there were some N-containing functional groups on the surface of the NCPs-treated biochar, which might lead to the desirable adsorption capability of toluene. On one hand, the $\mathrm{NH}_{3}$ generated from NCPs could enhance the hydrophobicity of carbon during the pyrolysis of stillages, promoting its affinity to volatile organic compounds. ${ }^{15}$ One the other hand, the addition of NCPs could help increase the content of basic functional groups, like pyridinic $\mathrm{N}$, and pyrrolic $\mathrm{N}$, on the carbon surface (Table 3 ), which could significantly increase the basicity of the carbon. The interaction of aromatic ring $\pi$ electron of toluene with carbon could be enhanced by the increase of carbon basicity, due to the donoracceptor mechanism, resulting in higher toluene uptake. ${ }^{43,44}$ In addition, the empty bed residence time (EBRT) of the adsorption reactor in our study was $0.24 \mathrm{~s}$, which was quite shorter than those for biological reactors (usually $>5 \mathrm{~s}$ ). ${ }^{5,6}$ Thus, compared with biological method, adsorption exhibited extremely higher removal rate for toluene and could effectively decrease the volume of reactor, resulting in a lower area occupation.

\section{Conclusions}

The results show that a novel N-doped biochar was prepared successfully using the stillage as the carbon precursor and different NCPs as the additives. The addition of NCPs could evidently increase the yield of biochar. All NCPs-treated biochar presented better pore structure than blank carbon, with higher $S_{\text {BET }}$ for AP-added carbon, at 481 and $798 \mathrm{~m}^{2} \mathrm{~g}^{-1}$ for AP-600 and AP-900, respectively. Furthermore, the $\mathrm{N}$ atoms could be successfully doped on the surface of prepared biochar, with relatively high contents of $\mathrm{N}$ for $\mathrm{AP}-600$, up to $4.16 \%$. The pyridinic $\mathrm{N}$ and pyrrolic $\mathrm{N}$ were the main $\mathrm{N}$ species at $600{ }^{\circ} \mathrm{C}$ and partial $\mathrm{N}$ species was transformed to graphitic $\mathrm{N}$ and oxidized $\mathrm{N}$ at $900{ }^{\circ} \mathrm{C}$. The interactions between plant-based biomass and NCPs could be divided into $\mathrm{P}$ route and $\mathrm{N}$ route, in which the generated $\mathrm{H}_{3} \mathrm{PO}_{4}$ and $\mathrm{NH}_{3}$ from NCPs played the dominant roles for the high yield $\mathrm{N}$ doped biochar. Moreover, the prepared biochar presented a desirable toluene adsorption behaviour, with the highest adsorption capacity at $496.2 \mathrm{mg} \mathrm{g}^{-1}$ for AP-900, which was ascribed to both abundant porous structure and $\mathrm{N}$ modified surface chemistry of the prepared biochar.

\section{Conflicts of interest}

There are no conflicts to declare.

\section{Acknowledgements}

This work is supported by National Nature Science Foundation of China (No. 51778383) and Science \& Technology Department of Sichuan Province (18GJHZ0125). 


\section{References}

1 H. Nigar, I. Julián, R. Mallada and J. Santamaría, Environ. Sci. Technol., 2018, 52, 5892-5901.

2 Y. Shu, Y. Xu, H. Huang, J. Ji, S. Liang, M. Wu and D. Y. C. Leung, Chemosphere, 2018, 208, 550-558.

3 W. K. Pui, R. Yusoff and M. K. Aroua, Rev. Chem. Eng., 2018, DOI: 10.1515/revce-2017-0057.

4 H. Wang, T. Wang, L. Han, M. Tang, J. Zhong, W. Huang and R. Chen, J. Mater. Res., 2016, 31, 516-525.

5 H. Chen, C. Yang, G. Zeng, S. Luo and G. Yu, Bioresour. Technol., 2012, 121, 199-204.

6 C. Yang, H. Qian, X. Li, Y. Cheng, H. He, G. Zeng and J. Xi, Trends Biotechnol., 2018, 36, 673-685.

7 J. Wang and C. Chen, Biotechnol. Adv., 2006, 24, 427-451.

8 J. Wang and C. Chen, Biotechnol. Adv., 2009, 27, 195.

9 S. Wu, H. He, X. Inthapanya, C. Yang, L. Lu, G. Zeng and Z. Han, Environ. Sci. Pollut. Res. Int., 2017, 24, 1-18.

10 Y. Luo, Doctoral thesis, Tsinghua University, 2010.

11 J. Chen, J. Yang, G. Hu, X. Hu, Z. Li, S. Shen, M. Radosz and M. Fan, ACS Sustainable Chem. Eng., 2016, 4, 1439-1445.

12 A. R. Mohamed, M. Mohammadi and G. N. Darzi, Renewable Sustainable Energy Rev., 2010, 14, 1591-1599.

13 J. H. Park, Y. S. Ok, S. H. Kim, J. S. Cho, J. S. Heo, R. D. Delaune and D. C. Seo, Chemosphere, 2016, 142, 77-83.

14 N. Zhu, T. Yan, J. Qiao and H. Cao, Chemosphere, 2016, 164, 32-40.

15 J. Mohammed, N. S. Nasri, M. A. Ahmad Zaini, U. D. Hamza and F. N. Ani, Int. Biodeterior. Biodegrad., 2015, 102, 245-255.

16 Y. Kan, Q. Yue, J. Kong, B. Gao and Q. Li, Chem. Eng. J., 2015, 260, 541-549.

17 K. C. Bedin, A. C. Martins, A. L. Cazetta, O. Pezoti and V. C. Almeida, Chem. Eng. J., 2016, 286, 476-484.

18 M. A. Yahya, Z. Al-Qodah and C. W. Z. Ngah, Renewable Sustainable Energy Rev., 2015, 46, 218-235.

19 M. Seredych and T. J. Bandosz, Energy Fuels, 2008, 22, 850859.

20 J. Song, W. Shen, J. Wang and W. Fan, Carbon, 2014, 69, 255263.

21 L. Fan, J. Chen, J. X. Guo, X. Jiang and W. J. Jiang, J. Anal. Appl. Pyrolysis, 2013, 104, 353-360.

22 C. J. Zhang, D. N. Yang, X. Jiang and W. J. Jiang, Environ. Technol., 2016, 37, 1895-1905.

23 W. Xing, C. Liu, Z. Zhou, L. Zhang, J. Zhou, S. Zhuo, Z. Yan, H. Gao, G. Wang and S. Z. Qiao, Energy Environ. Sci., 2012, 5, 7323-7327.
24 F. Sun, J. Gao, X. Liu, Y. Yang and S. Wu, Chem. Eng. J., 2016, 290, 116-124.

25 M. S. Shafeeyan, W. M. A. W. Daud, A. Houshmand and A. Shamiri, J. Anal. Appl. Pyrolysis, 2010, 89, 143-151.

26 M. Myglovets, O. I. Poddubnaya, O. Sevastyanova, M. E. Lindström, B. Gawdzik, M. Sobiesiak, M. M. Tsyba, V. I. Sapsay, D. O. Klymchuk and A. M. Puziy, Carbon, 2014, 80, 771-783.

27 K. Li, Y. Li and Z. Zheng, J. Hazard. Mater., 2010, 178, 553559.

28 W. Shen, S. Zhang, Y. He, J. Li and W. Fan, J. Mater. Chem., 2011, 21, 14036-14040.

29 R. Huang, H. Y. Liu, B. S. Zhang, X. Y. Sun, C. H. Liang, D. S. Su, B. N. Zong and J. F. Rong, ChemSusChem, 2014, 7, 3476-3482.

30 H. Guedidi, L. Reinert, J.-M. Lévêque, Y. Soneda, N. Bellakhal and L. Duclaux, Carbon, 2013, 54, 432-443.

31 F. Sun, J. Liu, H. Chen, Z. Zhang, W. Qiao, D. Long and L. Ling, ACS Catal., 2013, 3, 862-870.

32 C. L. Mangun, K. R. Benak, J. Economy and K. L. Foster, Carbon, 2001, 39, 1809-1820.

33 A. M. Puziy, O. I. Poddubnaya, R. P. Socha, J. Gurgul and M. Wisniewski, Carbon, 2008, 46, 2113-2123.

$34 \mathrm{H}$. Li, Master thesis, Inner Mongolia University of Science \& Technology, 2013.

35 M. Saleh, J. N. Tiwari, K. C. Kemp, M. Yousuf and K. S. Kim, Environ. Sci. Technol., 2013, 47, 5467-5473.

36 X. Tian, M. Zhou, C. Tan, M. Li, L. Liang, K. Li and P. Su, Chem. Eng. J., 2018, 775-785.

37 L. Tao, G.-B. Zhao, J. Qian and Y.-k. Qin, J. Hazard. Mater., 2010, 175, 754-761.

38 M. Jagtoyen and F. Derbyshire, Carbon, 1998, 36, 1085-1097.

39 M. A. Nahil and P. T. Williams, Biomass Bioenergy, 2012, 37, 142-149.

40 Y. Long, L. Ruan, X. Lv, Y. Lv, J. Su and Y. Wen, Chin. J. Chem. Eng., 2015, 23, 1691-1697.

41 M. A. Lillo-Ródenas, A. J. Fletcher, K. M. Thomas, D. CazorlaAmorós and A. Linares-Solano, Carbon, 2006, 44, 1455-1463.

42 A. Martinez de Yuso, M. T. Izquierdo, R. Valenciano and B. Rubio, Fuel Process. Technol., 2013, 110, 1-7.

43 Y. J. Tham, P. A. Latif, A. M. Abdullah, A. Shamala-Devi and Y. H. Taufiq-Yap, Bioresour. Technol., 2011, 102, 724-728.

44 N. Wibowo, L. Setyadhi, D. Wibowo, J. Setiawan and S. Ismadji, J. Hazard. Mater., 2007, 146, 237-242. 